\title{
Interleukin-1 $\beta$ induces the upregulation of caveolin-1 expression in a rat brain tumor model
}

\author{
LI-JUAN QIN ${ }^{1}$, YONG-SEN JIA $^{2}$, YI-BING ZHANG ${ }^{1}$ and YIN-HUAN WANG ${ }^{1}$ \\ ${ }^{1}$ Department of Physiology, School of Basic Medical Sciences; ${ }^{2}$ Department of Chinese Medicine, College of Traditional \\ Chinese Medicine, North China University of Science and Technology, Tangshan, Hebei 063000, P.R. China
}

Received September 28, 2015; Accepted February 18, 2016

DOI: $10.3892 /$ br.2016.618

\begin{abstract}
The aim of the present study was to investigate the expression of caveolin-1 in rat brain glioma tissue, and to determine whether interleukin-1 $\beta$ (IL-1 $\beta$ ) has a role in this process. Using glioma cells, a tumor-burdened rat model was established, and the expression of caveolin-1 protein in the tumor sites was significantly increased following intracarotid infusion of IL-1 $\beta$ (3.7 $\mathrm{ng} / \mathrm{kg} / \mathrm{min}$ ), as indicated by western blot analysis. The maximum value of the caveolin-1 expression was observed in tumor-burdened rats after 60 min of IL-1 $\beta$ perfusion, and which was significantly enhanced by vascular endothelial growth factor (VEGF). In addition, VEGF also significantly increased IL-1 $\beta$-induced blood tumor barrier (BTB) permeability. The results suggest that the IL-1 $\beta$-induced BTB permeability increase may be associated with the expression of caveolin-1 protein, and VEGF may be involved in this process.
\end{abstract}

\section{Introduction}

Glioma is one of the most common tumors of the central nervous system, and its high invasiveness leads to a high fatality rate (1). Chemotherapy is one of the most common clinical treatments; however, as a result of the existence of the blood tumor barrier (BTB), the effects of chemotherapy are limited (2); therefore, how to selectively open BTB without damage to the normal blood brain barrier is an urgent problem in the brain tumor treatment. Recent studies show that interleukin-1 $\beta$ (IL-1 $\beta$ ) could selectively increase the BTB permeability (3), but the exact mechanism remains to be elucidated.

Antitumor drugs cross the BTB into the brain tumors by two pathways: The paracellular and transcellular pathways (4). Due to different physical and chemical properties of drugs,

Correspondence to: Dr Li-Juan Qin, Department of Physiology, School of Basic Medical Sciences, North China University of Science and Technology, 57 South Road of Construction, Tangshan, Hebei 063000, P.R. China

E-mail: qinlj20012003@163.com

Key words: interleukin-1 $\beta$, glioma, vascular endothelial growth factor, caveolin-1, caveolae the vast majority of antineoplastic drugs cross the brain tumor tissue by the transcellular pathway (5). IL-1 $\beta$ has been shown to induce transcellular transport (6), suggesting that IL-1 $\beta$ induced an increase in BTB permeability that may be caused by vesicular transport rather than via the opening of endothelial tight junctions.

Caveolae participate in cell transport, metabolism and signal transduction. In the biochemical process, the caveolins protein family has a key role (7).

Caveolin-1 is the main structural protein of caveolae, which has an extremely important role in the activation and positioning of cell signaling molecules for vesicle rupture, endocytosis, fusion and exocytosis (8). Studies have shown that the protein expression level of caveolin-1 associated with BBB permeability regulation (9). Recently, a study has shown that vascular endothelial growth factor (VEGF) can be combined with caveolae to form a 'small hole' in the endothelial cell membrane, thereby promoting the transmembrane transport of biomolecules. IL-1 $\beta$ could induce the production of VEGF in stellate cells (10). Based on the aforementioned, we hypothesize that IL-1 $\beta$ could enhance transcellular transport of brain tumor microvascular through regulating the expression of caveolin-1, and this process can be mediated by VEGF.

To test the hypothesis, a model of rat C6 glioma was established, and investigated the effects of IL-1 $\beta$ to enhance BTB permeability by Evans blue (EB). In addition, whether IL-1 $\beta$ had an effect on caveolin-1 protein expression in brain tumor tissues and whether VEGF regulates this process by western blots and immunohistochemistry methods was investigated.

\section{Materials and methods}

Preparation of the rat C6 glioma model. The clean level male Wistar rats (200-220 g) were purchased from the Laboratory Animal Center of North China University of Science and Technology (Hebei, China). All the animal experiments were conducted in accordance with the National Institute of Health Guide for the Care and Use of Laboratory Animals, in addition to the policies of the North China University of Science and Technology and Chinese authority. First, 10\% chloral hydrate (3.5 $\mathrm{ml} / \mathrm{kg}$, intraperitoneal injection) anesthesia was used in the rats, and subsequently $1 \times 10^{6} \mathrm{C} 6$ cells were injected into the intracranial using a Hamilton syringe. Using a stereotaxic instrument, the coordinates were a location on the right side of 
the brain that targets the caudate nucleus, the coordinates of anterior fontanelle before $1 \mathrm{~mm}$ and sagittal suture immediately next to $3 \mathrm{~mm}$. Intracranial tumor formation was $\sim 2$ weeks after transplantation into the intracranial C6 cells.

Treatment of tumor-burdened rats. Tumor-burdened rats were randomized into two groups: Control and IL-1 $\beta$. For the control group, the rats were treated with saline solution. For the IL-1 $1 \beta$ group, IL-1 $(3.7 \mathrm{ng} / \mathrm{kg} / \mathrm{min})$ was infused into tumor-burdened rat brain via the common carotid artery for 30, 60 and $120 \mathrm{~min}$, respectively.

Measurement of BTB permeability by EB seepage quantity. First, rats were injected $2 \% \mathrm{~EB}(2 \mathrm{ml} / \mathrm{kg})$ via the tail vein for $2 \mathrm{~h}$, rats in the control and IL-1 $\beta$ groups were anesthetized with chloral hydrate and the brain with a tumor was weighed. Subsequently, brain tumor tissue was immersed in formamide solution $(1 \mathrm{ml} / 100 \mathrm{mg})$ at $60^{\circ} \mathrm{C}$ for $24 \mathrm{~h}$.

The optical density value was determined by spectrophotometry (at $620 \mathrm{~nm}$ ) to assess EB of the supernatant.

Western blot analysis of caveolin-1 and VEGF. The influence of IL-1 $\beta$ on caveolin-1 and VEGF protein expression levels were analyzed by western blot analysis. The protein homogenates of the brain tissue were prepared by homogenization in 10 volumes of pyrolysis buffer, and centrifugation at $17,000 \mathrm{x} g$ for $1 \mathrm{~h}$. The soluble protein content was determined by the Coomassie G250 binding method. The protein lysate was placed on a $12 \%$ SDS-polyacrylamide gel fraction (each sample was $12 \mu \mathrm{g} / \mathrm{lane}$ ), and subsequently transferred to a nitrocellulose membrane (Merck Millipore, Darmstadt, Germany). The membranes were blocked in blocking buffer overnight at $4^{\circ} \mathrm{C}$. The samples were incubated with rabbit polyclonal antibodies anti-caveolin-1 (cat. no. HYK-1453R; 1:400; Abcam, Cambridge, UK) and anti-VEGF (cat. no. sc-152; 1:400; Santa Cruz Biotechnology, Inc., Santa Cruz, CA, USA) were incubated for $2 \mathrm{~h}$. Caveolin-1 and VEGF bands were visualized using the enhanced chemiluminescene (ECL kit; Santa Cruz Biotechnology, Inc.).

Immunohistochemistry analysis of caveolin-1. The glioma tissues in the control and IL-1 $\beta$ groups at 15 min after infusion were fixed with $4 \%$ paraformaldehyde to carry out the immunohistochemical investigation. The sections were immunohistochemically stained with the donkey polyclonal antibody anti-caveolin-1 (diluted 1:100; Santa Cruz Biotechnology, Inc.) following standard procedures.

Statistical analysis. All the statistical analyses were performed with computer software (SigmaStat; SPSS, Inc., Chicago, IL, USA). All the data are expressed as mean \pm standard deviation. $\mathrm{P}<0.05$ was considered to indicate a statistically significant difference.

\section{Results}

Assessment of $B T B$ permeability by $E B$. Brain glioma tissue was stained in blue, while normal tissue did not stain. EB content in the glioma tissue was significantly increased in the IL-1 $\beta$ group at 60 -min infusion compared with the control

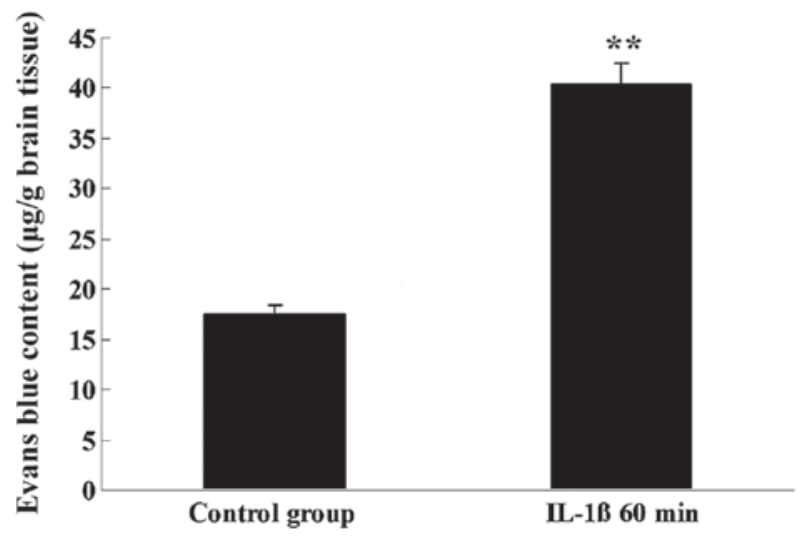

Figure 1. Permeability of the blood tumor barrier was assessed by Evans blue. Data are presented as mean \pm standard deviation $\left(\mathrm{n}=7\right.$ each). ${ }^{* *} \mathrm{P}<0.01$ vs. control group.

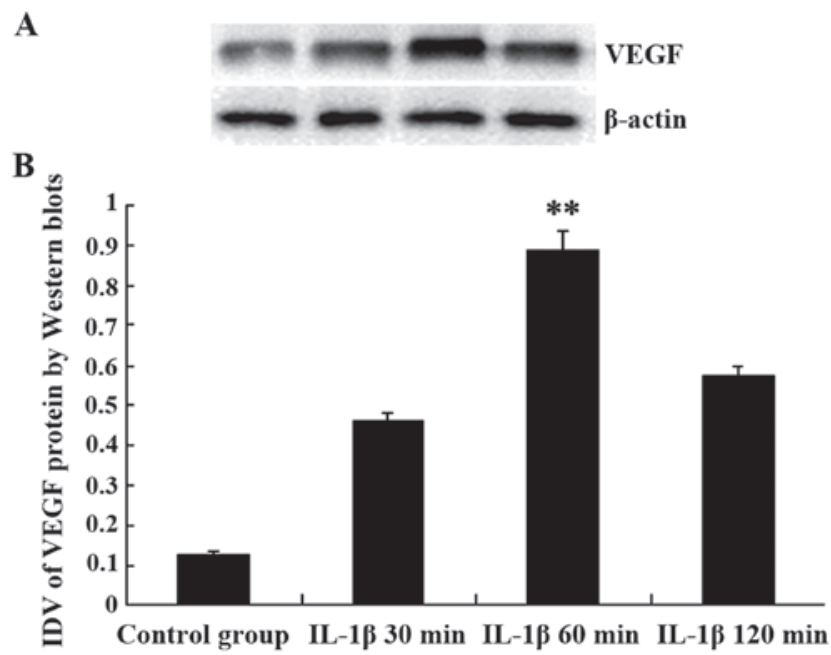

Figure 2. VEGF protein expression in the brain glioma tissues of the rats treated with IL-1 $\beta$. (A) Lane 1, control group; lane 2, IL-1 $\beta 30$ min group; lane 3, IL-1 $\beta 60$ min group; lane 4, IL-1 $\beta 120$ min group. Representative western blots illustrating the differences of caveolin-1. (B) Changes of the relative IDV of caveolin-1 $\left(\mathrm{n}=7\right.$ each). ${ }^{* *} \mathrm{P}<0.01$ vs. control group. VEGF, vascular endothelial growth factor; IL-1 $\beta$, interleukin-1 $\beta$; IDV, integrated density value.

group $(40.4 \pm 1.9$ and $17.2 \pm 0.8 \mu \mathrm{g} / \mathrm{g}$, respectively; $\mathrm{P}<0.05)$, as shown in Fig. 1.

$I L-1 \beta$ increases the expression of VEGF in tumor capillaries. VEGF expression in the rat brain glioma tissues in the control group was lower compared to the IL-1 $\beta$ group. Compared with the control group, the expression of VEGF protein was increased significantly at IL-1 $\beta$ group. The integrated density value (IDV) of VEGF at control, 30,60 and $120 \mathrm{~min}$ groups were $0.127 \pm 0.011,0.462 \pm 0.015$, $0.895 \pm 0.013$ and $0.574 \pm 0.062$, respectively, as shown in Fig. 2.

IL-1 $\beta$ increases the expression of caveolin-1 in the rat brain glioma model. Compared with the control group, the expression of caveolin-1 protein was increased significantly in the IL-1 $\beta$ infusion group. The IDV of caveolin-1 in the control, 30,60 and $120 \mathrm{~min}$ groups were $0.369 \pm 0.019,1.158 \pm 0.041$, 
A

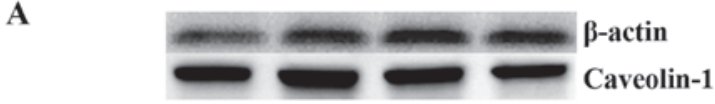

B

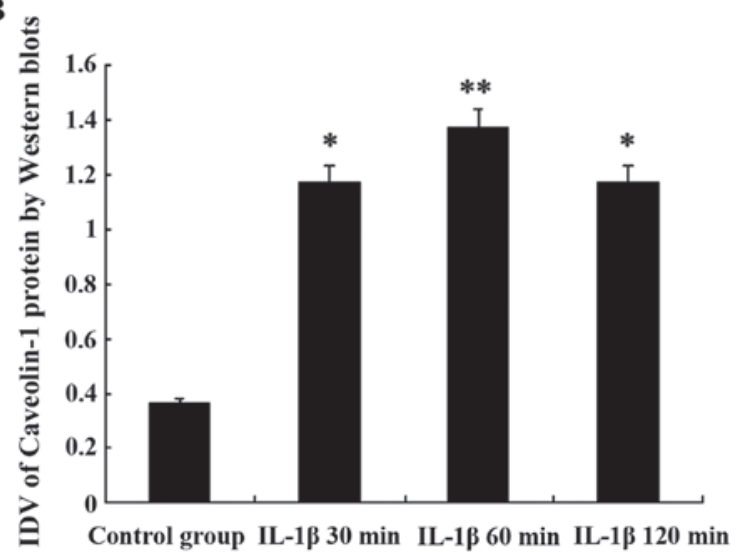

Figure 3. Caveolin-1 protein expression in the brain tumor tissues of the rats treated with IL-1 $\beta$. (A) Lane 1, control group; lane 2, IL-1 330 min group;

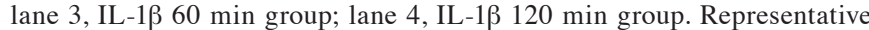
western blots illustrating the differences of caveolin-1. (B) Changes of relative IDV of caveolin-1 ( $\mathrm{n}=7$ each). ${ }^{* *} \mathrm{P}<0.01,{ }^{*} \mathrm{P}<0.05$ vs. control group. IL-1 $\beta$, interleukin-1 $\beta$; IDV, integrated density value.
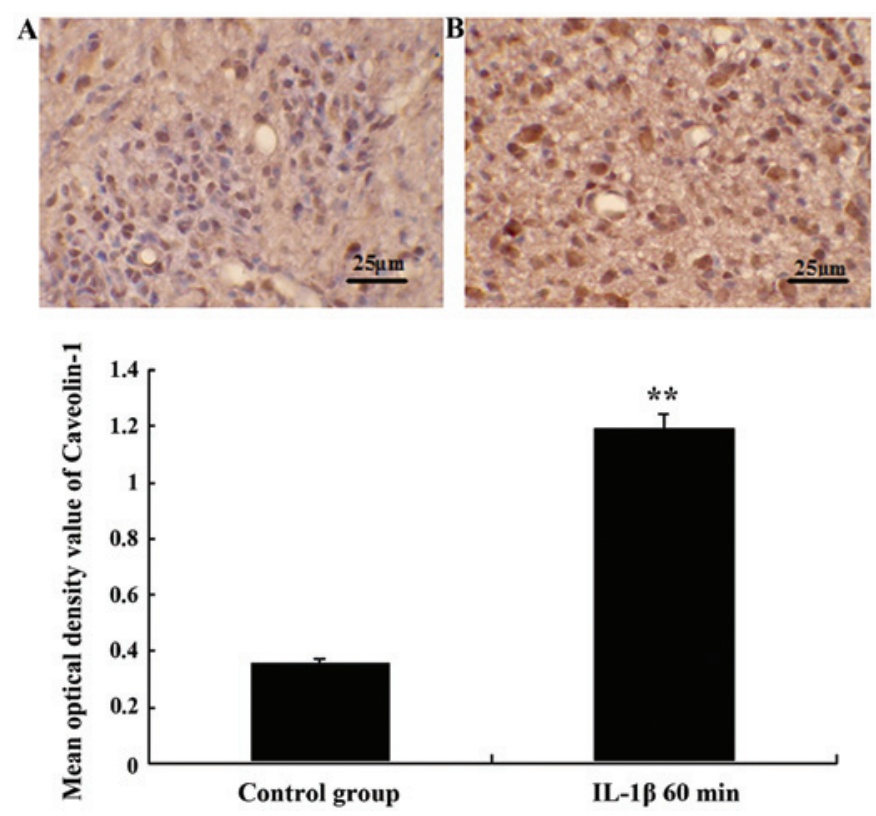

Figure 4. Caveolin-1 expression in the brain tumor tissues of the rats treated with IL-1 $\beta$. A representative example of caveolin-1 immunohistochemical images in the different groups. (A) Control and (B) IL-1 130 min groups. Mean optical density value is shown $\left(\mathrm{n}=7\right.$, each). ${ }^{* *} \mathrm{P}<0.01$ vs. control group. IL-1 $\beta$, interleukin-1 $\beta$.

$1.365 \pm 0.078$ and $1.172 \pm 0.084$, respectively, as shown in Fig. 3.

Expression of caveolin-1 in tumor capillaries and cells following the IL-1 $\beta$ infusion. Caveolin-1-like immunoreactivity showed that caveolin-1 protein expression was further enhanced in tumor capillaries and tumor cells following the IL-1 $\beta$ infusion, and reaches its maximum after IL-1 $1 \beta$ infusion for $60 \mathrm{~min}$. The mean optical density values of caveolin- 1 were $0.192 \pm 0.021$ and $0.359 \pm 0.018$, respectively, as shown in Fig. 4 .

\section{Discussion}

Malignant glioma is the most common type of brain tumor. The blood brain barrier (BBB) is the main factor limiting its drug treatment $(1,11)$. Selective destruction of $B B B$, using antitumor drugs through the $\mathrm{BBB}$, is a promising therapy for invasive glioma.

BBB consists of capillary endothelial cells, the basement membrane, pericytes and astrocytic foot processes. There are close continuous tight junctions between the brain capillary endothelial cells. Our previous studies demonstrated that IL-1 $\beta$, a cell factor, could increase BTB permeability (12). However, the exact mechanism of the increase of IL-1 $\beta$-induced BTB permeability remains to be elucidated.

The study by Allan and Rothwell (13) demonstrated that the main functional role of IL- $1 \beta$ is in the vascular endothelial cells. VEGF has an extremely important role in the proliferation, migration and formation of blood vessels (14-18). Our experimental results show that IL-1 $\beta$ could induce the expression of VEGF in tumor capillaries; the peak appears at $60 \mathrm{~min}$ after infusion and subsequently decreased. This trend is consistent with the temporal changes in the permeability of BTB. Those results suggest that VEGF may mediate the process of BTB permeability by IL-1 $\beta$; however, the associated mechanism requires further investigation.

Caveolin-1 is the symbolic protein of the caveolae, and has an important role in maintaining the shape, structure and function of caveolae, particularly the endocytosis of endothelial cells (19). Endocytosis of endothelial cells did not occur following knockout caveolin-1 (20). Furthermore, caveolin-1 is associated with the transport of BBB, and its protein expression is associated with the increase in BBB permeability $(9,21)$. To clarify the mechanism of the IL-1 $\beta$-induced BTB permeability increase, in the present study, IL-1 $\beta$ was shown to increase the expression of caveolin-1 protein, and the maximum expression level appeared at $60 \mathrm{~min}$ after IL-1 $\beta$ infusion. The permeability of BTB increased following IL- $1 \beta$ infusion and its peak also appeared at $60 \mathrm{~min}$, which corresponds with the increased expression of caveolin-1 and VEGF. Those results suggest that VEGF is a key signaling molecules in IL- $1 \beta$ increased BTB permeability.

In conclusion, the mechanism of the IL-1 $\beta$ increase in BTB permeability is extremely complex. The present results show that the VEGF/caveolin-1 signaling pathways may be one of its mechanisms. These results suggest that the mechanism of the IL-1 $\beta$ increase of BTB permeability may be through the VEGF increase in the endocytosis of cerebral microvascular endothelial cells.

\section{Acknowledgements}

The present study was supported by the Natural Science Foundation of China (grant nos. 81101912 and 81201048), the Hebei Province Science and Technology Support Program (grant no. 152777189), the Hebei Province Administration of Traditional Chinese Medicine (grant no. 2014195) and the Hebei Province Department of Health and Family Planning Commission (grant no. 20150491). 


\section{References}

1. Drappatz J, Schiff D, Kesari S, Norden AD and Wen PY: Medical management of brain tumor patients. Neurol Clin 25 1035-1071, ix, 2007.

2. Laquintana V, Trapani A, Denora N, Wang F, Gallo JM and Trapani G: New strategies to deliver anticancer drugs to brain tumors. Expert Opin Drug Deliv 6: 1017-1032, 2009.

3. Sadowska GB, Chen X, Zhang J, Lim YP, Cummings EE Makeyev O, Besio WG, Gaitanis J, Padbury JF, Banks WA and Stonestreet BS: Interleukin-1 $\beta$ transfer across the blood-brain barrier in the ovine fetus. J Cereb Blood Flow Metab 35: 1388-1395, 2015.

4. Komarova Y and Malik AB: Regulation of endothelial permeability via paracellular and transcellular transport pathways. Annu Rev Physiol 72: 463-493, 2010.

5. Salama NN, Eddington ND and Fasano A: Tight junction modulation and its relationship to drug delivery. Adv Drug Deliv Rev 58: 15-28, 2006.

6. Dohgu S, Fleegal-DeMotta MA and Banks WA: Lipopolysaccharide-enhanced transcellular transport of HIV-1 across the blood-brain barrier is mediated by luminal microvessel IL-6 and GM-CSF. J Neuroinflammation 8: 167, 2011.

7. Quest AF, Gutierrez-Pajares JL and Torres VA: Caveolin-1: An ambiguous partner in cell signalling and cancer. J Cell Mol Med 12: 1130-1150, 2008.

8. Sun SW, Zu XY, Tuo QH, Chen LX, Lei XY, Li K, Tang CK and Liao DF: Caveolae and caveolin-1 mediate endocytosis and transcytosis of oxidized low density lipoprotein in endothelial cells. Acta Pharmacol Sin 31: 1336-1342, 2010.

9. Nag S, Venugopalan R and Stewart DJ. Increased caveolin-1 expression precedes decreased expression of occludin and claudin-5 during blood-brain barrier breakdown. Acta Neuropathol 114: 459-469, 2007.

10. Ben Menachem Zidon O, Ben Menahem Y, Ben Hur T and Yirmiya R: Intra- hippocampal transplantation of neural precursor cells with transgenic over- expression of IL-1 receptor antagonist rescues memory and neurogenesis impairments in an Alzheimer's disease model. Neuropsychopharmacology 13: 2736, 2013.
11. Hayashi Y, Yoshida Y and Hamada J: Blood-tumor barrier in malignant brain tumor. No Shinkei Geka 34: 983-999, 2006 (In Japanese).

12. Qin LJ, Xue YX, Gu YT, Zhang ZY, Zhang T and Sun N: Effect and mechanisms of interleukin- $1 \beta$ in process of opening the blood-brain barrier by bradykinin. Chinese Pharmacological Bulletin 1: 58-61, 2012.

13. Allan SM and Rothwell NJ: Cytokines and acute neurodegeneration. Nat Rev Neurosci 2: 734-744, 2001.

14. Davies DC: Blood-brain barrier breakdown in septic encephalopathy and brain tumours. J Anat 200: 639-646, 2002.

15. Faehling M, Kroll J, Föhr KJ, Fellbrich G, Mayr U, Trischler G and Waltenberger J: Essential role of calcium in vascular endothelial growth factor A-induced signaling: Mechanism of the antiangiogenic effect of carboxyamidotriazole. FASEB J 16: 1805-1807, 2002.

16. Argaw AT, Asp L, Zhang J, Navrazhina K, Pham T, Mariani JN, Mahase S, Dutta DJ, Seto J, Kramer EG, et al: Astrocyte-derived VEGF-A drives blood-brain barrier disruption in CNS inflammatory disease. J Clin Invest 122: 2454-2468, 2012.

17. Wei M, Li H, Huang H, Xu D, Zhi D, Liu D and Zhang Y: Increased expression of EMMPRIN and VEGF in the rat brain after gamma irradiation. J Korean Med Sci 27: 291-299, 2012.

18. Kim J and Jung Y: Different expressions of AQP1, AQP4, eNOS, and VEGF proteins in ischemic versus non-ischemic cerebropathy in rats: Potential roles of AQP1 and eNOS in hydrocephalic and vasogenic edema formation. Anat Cell Biol 44: 295-303, 2011.

19. Lajoie P and Nabi IR: Regulation of raft-dependent endocytosis. J Cell Mol Med 11: 644-653, 2007

20. Drab M, Verkade P, Elger M, Kasper M, Lohn M, Lauterbach B, Menne J, Lindschau C, Mende F, Luft FC, et al: Loss of caveolae, vascular dysfunction, and pulmonary defects in caveolin-1 gene-disrupted mice. Science 293: 2449-2452, 2001.

21. Zhong Y, Smart EJ, Weksler B, Couraud PO, Hennig B and Toborek M: Caveolin-1 regulates human immunodeficiency virus-1 Tat-induced alterations of tight junction protein expression via modulation of the Ras signaling. J Neurosci 28: 7788-7796, 2008. 